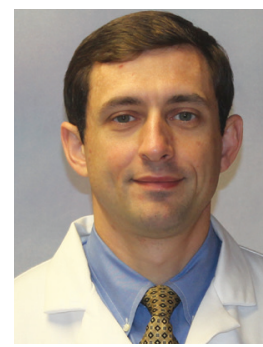

\title{
MODERN INTERVENTIONAL MANAGEMENT OF STROKE
}

\author{
Andrew S. Ferrell, M.D. a; Y. Jonathan Zhang, M.D.b; Orlando Diaz, M.D.b; \\ Richard Klucznik, M.D.'; Gavin W. Britz, M.D., M.P.H. ${ }^{b}$ \\ a University of Tennessee Medical Center Knoxville, Knoxville, Tennessee; bHouston Methodist Hospital, \\ Houston, Texas
}

A.S. Ferrell, M.D.

\begin{abstract}
Acute ischemic stroke continues to be one of the leading causes of disability and death and is a financial burden to an already taxed health care system. Much research and investigation has been carried out over the past decade on various recanalization devices aimed at restoring cerebral blood flow. Despite the rapidly improving technical abilities of these devices, it has been difficult to demonstrate corresponding improved clinical outcomes. This article will describe the application of the most recent generation of these devices and briefly discuss the ongoing discrepancy between these technical achievements and stroke outcomes
\end{abstract}

\section{Introduction}

Stroke remains the fourth leading cause of death in the United States, with a yearly incidence of nearly 800,000; it also is the leading cause of disability, with a projected cost of more than $\$ 60$ billion for the year 2015.1,2 Roughly $85 \%$ of strokes are ischemic in nature, with the majority being thromboembolic and thus potentially amenable to various treatment strategies to restore blood flow. ${ }^{3}$ The restoration of cerebral perfusion by vessel recanalization, either spontaneously or therapeutically, has been shown in the literature to improve outcomes and reduce mortality in the setting of acute ischemic stroke, ${ }^{4,5}$ and several generations of both pharmacological therapies and interventional mechanical devices have been developed with the goal of achieving this.

\section{Intravenous Fibrinolysis}

Intravenous tissue plasminogen activator (IV rt-PA) was approved by the U.S. Food and Drug Administration (FDA) following publication of the National Institute of Neurological Disorders and Stroke rt-PA Stroke Study more than 16 years ago, and numerous further studies have demonstrated its success. ${ }^{6}$ IV rt-PA remains to this day the only level 1 evidence-supported, FDA-approved treatment for acute ischemic stroke (AIS). Despite the undeniable success of IV rt-Pa, there are limitations to its ability and widespread application. First, the total number of patients with AIS who ultimately are candidates for therapy is a small fraction of the total volume (7\%-15\%), since many are hemorrhagic in nature, small-vessel occlusions, transient ischemic attacks, end-of-life strokes, and mild strokes-all of which are contraindications. ${ }^{7}$ Despite evidence in recent years validating the extension of the recommended time window for IV rt-PA administration from 3 hours to 4.5 hours following the onset of symptoms, ${ }^{8}$ in most communities only somewhere between $1 \%$ and $7 \%$ of patients seek or receive medical care within the time constraints for revascularization therapy. ${ }^{9}$ These factors collectively result in a small volume of patients ultimately receiving the drug. Another severe limitation of IV rt-PA is in the setting of large vessel occlusions, in which the overall recanalization rate less than $50 \%{ }^{4}$ These and other factors have garnered interest in various intraarterial therapies aimed at improving reperfusion in this setting.

\section{Intra-arterial Fibrinolysis}

Initial efforts beyond IV therapy first focused on the intra-arterial (IA) administration of fibrinolytics, proven effective for use up to 6 hours after the onset of symptoms in the Pro-Urokinase for Acute Cerebral Thromboembolism II (PROACT-II) trial. ${ }^{10}$ In this study, 180 patients with proximal middle cerebral artery (MCA) occlusions were treated in randomized fashion with IA pro-urokinase and compared to those receiving IV heparin alone. Patients receiving IA pro-urokinase demonstrated a $66 \%$ recanalization rate, with $40 \%$ having good clinical neurological outcomes after 90 days (i.e., a modified Rankin score of 2 or less). These numbers have remained comparable to all other advancements seen with mechanical devices. While other trials have demonstrated a trend in favor of IA fibrinolytic therapy, ${ }^{11}$ statistical significance was not achieved due to inadequate powering of the studies. Unfortunately, PROACT-II remains the only randomized trial definitively supporting this therapy, and pro-urokinase, which was used in the trial, is not available in the United States. Thus despite its effectiveness, the use of IA rt-PA technically remains off label. This, along with the perception that mechanical devices allow for timelier and easier recanalization, has resulted in a somewhat limited application in favor of mechanical thrombectomy. Most operators currently seem to use IA rt-PA as adjunctive therapy to mechanical devices or for distal small branch occlusions that may be difficult to access with larger, more robust mechanical devices.

\section{Mechanical Thrombectomy}

Subsequent technical developments have centered on various mechanical thrombectomy devices that have the theoretical advantage of improved and timelier recanalization rates compared to that seen with IV or IA fibrinolytics, giving these devices the advantage of extended time windows for their application. It 
was also hoped that these devices would result in lower rates of hemorrhagic conversion, and ultimately a better safety profile, compared to systemically administered fibrinolytics. These devices are primarily used for patients ineligible for IV rt-PA or those who have failed IV therapy, although data supporting the later indication has recently been brought into question.

The Mechanical Embolus Removal in Cerebral Ischemia (Merci Retriever ${ }^{\circledR}$, Concentric Medical, Inc., Mountain View, CA) was the first mechanical retrieval device to be cleared by the FDA for IA mechanical thrombectomy in 2004. The Merci Retriever system is a microcatheter-based device that is deployed after the microcatheter navigates its way through an occlusive clot. The corkscrew nature of the device immerses into the clot, which can then be withdrawn with the microcatheter into an extracranial balloon occlusion guide catheter for removal. Suction aspiration on the guide catheter is also performed to aid retrieval. The device went through several generational modifications and three nonrandomized, prospective, single-arm feasibility trials demonstrating the effectiveness of the procedure, the largest being the Multi-MERCI trial that enrolled 164 patients. In this study, patients were treated on average at 4.3 hours after the onset of symptoms, and the device achieved a recanalization rate of $57.3 \%$. In patients also receiving adjuvant therapy, the recanalization rate increased to $69.5 \%$. There was a $9.8 \%$ rate of symptomatic intracranial hemorrhage $(\mathrm{SICH})$ and a 90 -day mortality of $34 \%$, with $36 \%$ of patients showing good neurologic outcome at 90 days (modified Rankin score, mRS, of $0-2){ }^{12}$

The second major generation of mechanical thrombectomy devices arrived with the release of the Penumbra system (Penumbra, Inc., Alameda CA) in 2006. This microcatheter-based system is navigated into the proximal face of an occlusive clot rather than through the lesion, and the clot is removed through suction aspiration and clot "maceration" by a separation wire. The system was tested in the prospective, single-arm, multicenter Penumbra Pivotal Stroke Trial, which enrolled and treated 125 patients with acute ischemic stroke. All subjects had National Institutes of Health Stroke Scale scores (NIHSS) $\geq 8$ presenting within 8 hours of symptom onset, and they had an angiographic occlusion of a treatable large intracranial vessel (Thrombolysis In Myocardial Infarction [TIMI] grade 0 or 1). Revascularization of TIMI 2-3 was achieved in $81.6 \%$ of patients, with an $11.2 \%$ rate of $\mathrm{SICH}$ and a $32.8 \%$ mortality rate at 90 days. Good clinical outcome (mRS $0-2$ ) of $25 \%$ at 90 days also was achieved..$^{13}$ Although the $82 \%$ recanalization rate proved excellent angiographic success exceeding that achieved with fibrinolytics or the Merci Retriever, the corresponding improvement in clinical outcome $(>4$ point improvement in NIHSS; mRS 0-2 at 90-day follow-up) was less than expected and did not follow in linear fashion the degree of improved revascularization. This was one of the first studies to note the growing disparity between technical success of recanalization and lack of significant improvement in clinical outcomes compared to previous therapies.

One of the most exciting technical advancements in stroke in recent years is the release of stent retriever technology. Two main devices are currently being marketed in the United States: the Solitaire ${ }^{\mathrm{TM}}$ FR Revascularization Device (Covidien, Mansfield, MA) and the Trevo ${ }^{\circledR}$ Pro Retriever (Concentric Medical, Mountain View, CA). The Solitaire FR device is an intracranial stent initially designed for assistance in aneurysm embolization; it subsequently was found to have significant capabilities as a mechanical clot retrieval device for AIS. ${ }^{14-21}$ Both devices have a similar design and are essentially modified intracranial stents deployed by a standard microcatheter technique, yet they have the unique property of being fully retrievable. When the stent retriever is migrated into an occlusive clot and deployed, the radial force of the stent compresses thrombus against the arterial wall, allowing immediate partial restoration of flow and enhancing the effects of any previously administered thrombolytic agents. While the stent is deployed over several minutes, the clot becomes trapped within the interstices and is subsequently retrieved, along with the stent, into the extracranial guide catheter (Figure 1). ${ }^{17}$ The stent can be applied repeatedly to remove residual or resistant clot and is accessible to
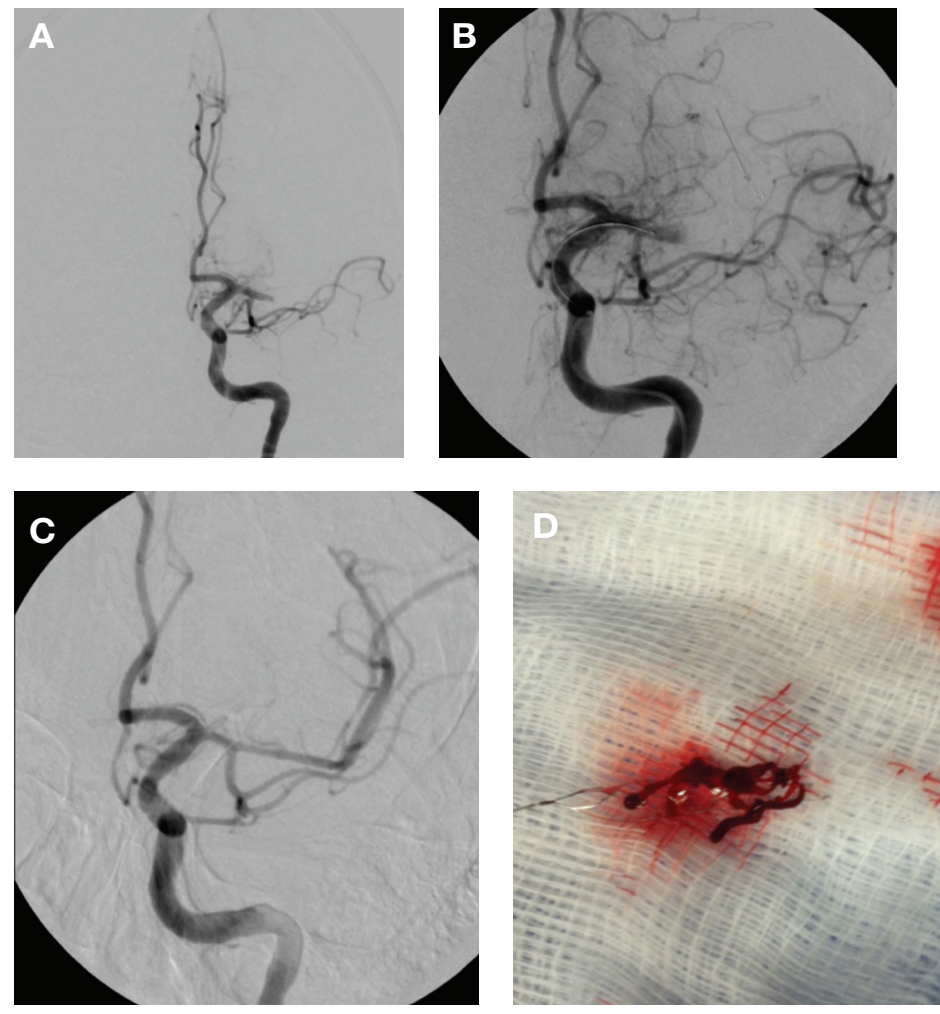

Figure 1. (A) Left internal carotid artery (ICA) arteriogram demonstrates complete thrombotic occlusion ( $\mathrm{TICl} 0$ ) of the $\mathrm{M} 1$ segment of the left middle cerebral artery (MCA). (B) Intraprocedural left ICA injection demonstrates microcatheter deployment of a $4 \times 20 \mathrm{~mm}$ Solitaire $^{\mathrm{TM}}$ stent revascularization device (ev3 Endovascular, Inc., Plymouth, MN). Distal markers can be seen deployed against the nonopacified distal vessel (grey arrow). (C) After removal of the Solitaire device, left ICA injection shows complete $(\mathrm{TICl} 3)$ reperfusion of previously noted left $\mathrm{M} 1$ occlusion. (D) Back table image of the Solitaire stent reveals significant retrieved clot from the left MCA.

small distal arteries (M2 and P2 branches, for example).

The device is enhanced by the use of a balloon occlusion guide catheter. Placed in the target carotid or vertebral artery, these catheters allow for flow arrest while the stent retriever is being withdrawn. In addition, the balloon guide allows for high-volume suction aspiration of the proximal vessel to hopefully remove any free clot that becomes dislodged from the interstices of the stent during removal. The combination of flow arrest with proximal suction aspiration has the potential advantage of preventing downstream emboli during clot removal and seems to be a critical adjunct to the success of this new technology. In an oral abstract presented at the 2013 Society of NeuroInterventional Surgery 
annual meeting, investigators reviewed 354 patients treated with the Solitaire device in the North American Solitaire Stent-Retriever Stroke Registry (NASA). ${ }^{22}$ They compared the effectiveness of the procedure both with and without the balloon guide catheter and found some interesting results. Procedure time was found to be shorter with the balloon guide catheter (120 vs. 161 minutes, $\mathrm{P}=$ $0.02)$, less rescue therapy was required ( $20 \%$ vs. $28.6 \%, \mathrm{P}=0.05)$, good recanalization rates were higher (TICI 2b/3: 75\% vs. 70\%; TICI 3: $53 \%$ vs. $32.5 \%, P>.001$ ), discharge NIHSS was lower (mean 12 vs. 17.5; $\mathrm{P}=.02$ ), and 3-month clinical outcomes were improved $(51.6 \%$ vs. $35.8 \% ; \mathrm{P}=.02)$ with this adjunctive procedure. ${ }^{22}$ One outcome that was not different between the two groups, and somewhat a surprise as this is a touted potential advantage, was the occurrence of downstream emboli or emboli to new territories. ${ }^{22}$ While randomized head-to-head comparisons still need to be performed to completely delineate the advantages of the balloon guide catheter, many operators are finding it highly useful and routinely incorporating it into their thrombectomy procedures.

The hope is that stent retrievers will allow more complete and faster thrombectomy compared to currently available devices. The recent release of the Solitaire with the Intention for Thrombectomy (SWIFT) study indeed supported this hypothesis. SWIFT was an open-label, randomized, blinded, multicenter trial evaluating the effectiveness of the Solitaire FR Revascularization Device against the Merci Retriever for mechanical revascularization of large vessel occlusions in the setting of AIS. SWIFT demonstrated a significantly higher recanalization rate without SICH with the Soltaire device compared to the Merci Retriever (61\% vs. $24 \%)^{23,24}$ If only successful recanalization is considered (with or without $\mathrm{SICH}$ ), the Solitaire device was able to open $88.9 \%$ of occluded vessels compared to $67.3 \%$ with the Merci device. ${ }^{23,}{ }^{24}$ In those patients treated with the Solitaire device, 58\% had good 3-month neurological outcome $(\mathrm{mRS} \leq 2)$ compared to $33 \%$ with the Merci device. ${ }^{24}$ In addition, the 3-month mortality rate with the Solitaire and Merci devices was $17 \%$ and $38 \%$, respectively. ${ }^{23,24}$

The Trevo Pro Retriever also demonstrated significant superiority to Merci in a randomized controlled trial. In the TREVO 2 study (Trevo versus Merci retrievers for thrombectomy revascularization of large vessel occlusions in acute ischemic stroke), the device was able to achieve thrombolysis in cerebral infarction (TICI) scores of 2 or greater in $86 \%$ of treated patients compared to $60 \%$ in the Merci group. ${ }^{25}$ In addition, a 90 -day good clinical outcome (mRS 0-2) was achieved in 40\% with Trevo versus $22 \%$ with Merci. $^{25}$

Like all new devices, stent retriever technology carries its own set of problems. One issue is emboli to new territories when the stent retriever and clot are withdrawn, reported to occur in up to $14 \%$ of cases (Figure 2). ${ }^{24,}{ }^{25}$ In addition, although uncommon, unintentional breakage and inadvertent deployment of the Solitaire device has been reported. ${ }^{15}$

Recent advances in catheter design to help navigate larger bore devices into the intracranial circulation have facilitated the development of the ADAPT technique-a direct aspiration first pass technique for stroke thrombectomy. This technique was recently introduced as a faster, cheaper, and potentially more efficacious alternative to stent retriever technology. ${ }^{26}$ Recently, Penumbra has modified their suction retrieval system with the new $5 \mathrm{Max}^{\mathrm{TM}}$ Reperfusion Catheter, which has an increased surface and improved trackability compared to the older Penumbra 054 catheter. This allows the catheter to be navigated into the face of
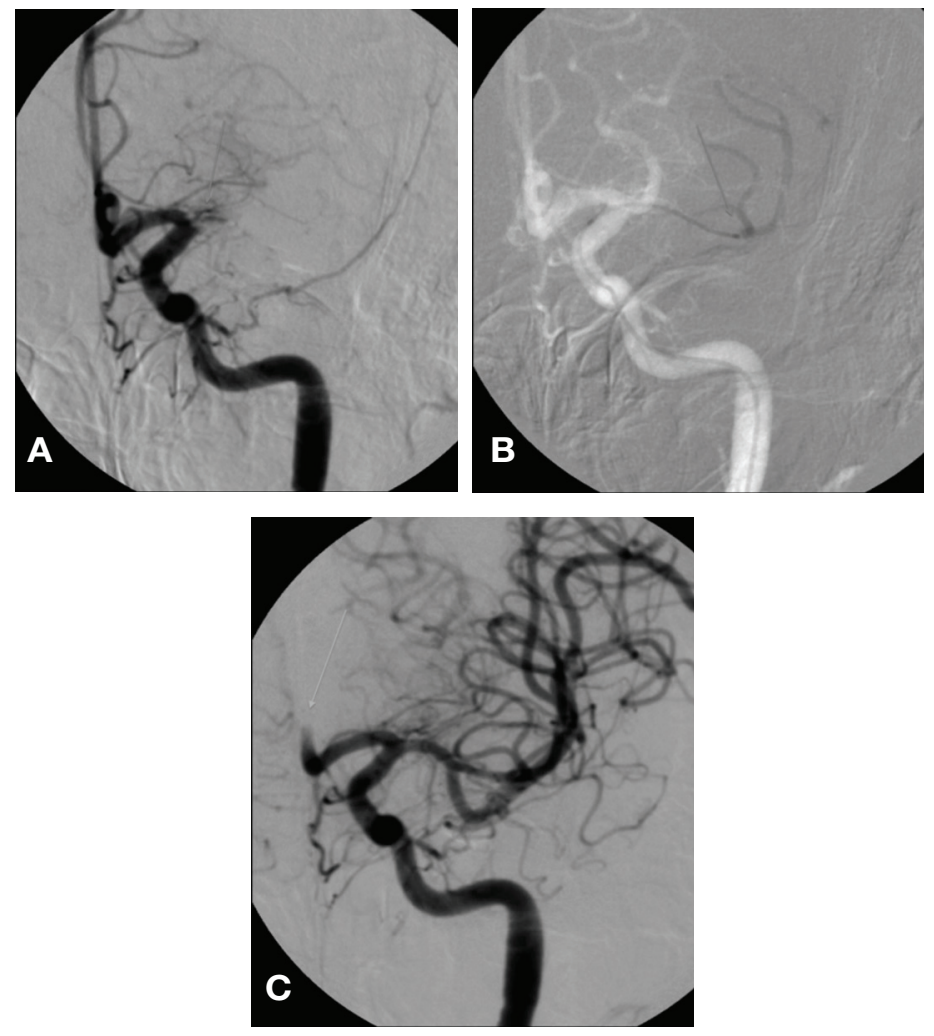

Figure 2. (A) Left internal carotid artery (ICA) injection reveals complete thrombotic occlusion ( $\mathrm{TICl}$ ) of the $\mathrm{M} 1$ segment of the left middle cerebral artery (MCA) (grey arrow). (B) The microcatheter has been migrated past the occlusive clot with contrast injection (grey arrow) confirming intraluminal location distal to the embolus. A $4 \times 15 \mathrm{~mm}$ Solitaire stent was subsequently deployed, spanning the lesion. (C) After removal of the Solitaire device, left ICA injection reveals inadvertent embolization of the previously noted $\mathrm{M} 1$ occlusive thrombus into the left anterior cerebral artery (grey arrow). While TICI 3 flow was restored in the MCA, inadvertent embolic events in new vascular territories are being seen with stent retriever technology. The new embolus was partially treated with intraarterial t-PA and Penumbra system suction aspiration (not shown).

an occlusive intracranial clot using a 0.016-inch microwire alone or with the aid of a second telescoping microcatheter. ${ }^{26}$ Once the clot is engaged, the reperfusion catheter can be aspirated while withdrawn into the guide catheter to remove the clot in its entirety. In a recent retrospective analysis of 37 patients at six institutions, the ADAPT technique was successful alone (with no adjunctive therapy or device) in 28 of the cases $(75 \%) .{ }^{26}$ All patients were ultimately successfully revascularized with a remarkable average time of 28.1 minutes ( $7 \mathrm{~min}$. in one case) from groin puncture to at least TICI $2 b$ recanalization. ${ }^{26}$ In addition, TICI 3 recanalization was achieved $65 \%$ of the time, with a number higher than that reported in previous series. ${ }^{24,25,27,28}$ On average, patients presented with an admitting NIHSS score of 16.3 and improved to 4.2 by the time of discharge. ${ }^{26}$ This technique has created much interest as a potential way of improving the quality of thrombectomy, with complete thrombus removal without downstream emboli, and is potentially faster than other mechanical devices. Direct suction aspiration also has a potential cost-saving advantage, as stent retrievers remain expensive devices for hospital budgets. This technique has not yet been compared head to head with stent retrieval devices, and the complete implementation of this technique remains to be seen. 


\section{Recent Trials-Technology and Revascularization vs. Patient Outcomes}

It is clear that our technical ability to open occluded vessels with the newer generations of mechanical devices has advanced to an impressive level. Attempts to prove the clinical effectiveness and adequacy of these devices as compared to IV therapy alone or in combination over the last decade has been difficult. The recent halting and subsequent data release of the Interventional Management of Stroke (IMS) III trial was yet another discouraging blow to the field. IMS III was a randomized, multicenter, openlabel clinical trial designed to determine if a combination of IV rt-PA and an approved IA therapy (an FDA approved mechanical thrombectomy device and/or intra-arterial rt-PA) was superior to IV rt-PA alone. ${ }^{29}$ The trial was to be stopped if it was unlikely that a $10 \%$ difference in favorable outcomes (mRS 0-2) would be seen at 90 days between the two groups. ${ }^{29}$ The data safety monitoring board stopped the trial after enrolling 656 of the intended 900 patients, as initial data seemed unlikely that the combined treatment was going to show a more favorable outcome than IV rt-PA alone. The number of patients with mRS $\leq 2$ at 90 days did not differ significantly according to treatment $(40.8 \%$ with endovascular therapy and $38.7 \%$ with IV rt-PA). Findings in the endovascular-therapy and IV rt-PA groups were similar for mortality at 90 days (19.1\% and $21.6 \%$, respectively) and $\mathrm{SICH}$ within 30 hours after initiation of treatment $(6.2 \%$ and $5.9 \%$, respectively). ${ }^{30}$ More discouraging was that no clinical improvement was seen despite the fact that significantly higher recanalization rates at 24 hours were seen in the endovascular $\operatorname{arm}(85.7 \%$ vs. $60.8 \%),{ }^{30}$ further pointing towards the discrepancy between recanalization and improved clinical outcomes. However, there were nonsignificant trends toward benefit for endovascular therapy in patients with the most severe stroke symptoms (NIHSS $\geq 20$ ) and in those treated most rapidly. ${ }^{31,32}$ Post-hoc analysis also showed better outcomes in patients with occlusion of the internal carotid artery terminus but no difference in those with M1 occlusions. ${ }^{31,32}$ It is important to note that the monitoring board clarified that safety concerns were not the reason for halted enrollment. There was no statistical difference with regards to SICH or mortality, and outcomes were similar. Therefore, mechanical thrombectomy remains an acceptable alternative to patients ineligible for IV rt-PA who present within 4.5 hours of symptom onset. At this point endovascular therapy remains investigational or an alternative only for selected patients in expanded time windows or for those not responding to IV rt-PA.

Recently, the Italian SYNTHESIS Expansion trial attempted to ascertain if endovascular therapy would be superior to IV therapy in patients presenting within eligible time windows for either option. This trial randomized 362 patients to treatment with IV rt-PA alone within 4.5 hours of symptom onset $(n=181)$ or with endovascular therapy alone (IA rt-PA or mechanical thrombectomy at the operator's discretion, $\mathrm{n}=181$ ) within 6 hours of symptom onset. ${ }^{33}$ As with the other studies, primary endovascular therapy in this trial was not superior to IV therapy alone, with the proportion of patients achieving an mRS of 0 to 1 at 90 days, showing no statistical difference (34.8\% IV rt-PA vs. 30.4\% endovascular therapy; $\mathrm{P}=.16) .{ }^{33}$ It should be noted that time from stroke onset to treatment was one hour longer in the endovascular arm $(3.75$ vs. 2.75 hrs; $\mathrm{P}<.001){ }^{33}$

Much effort has also been aimed at using advanced imaging methods to identify patterns of ischemic penumbra and to select patients most likely to benefit from intervention based on these patterns. This approach was evaluated in the MR RESCUE trial, in which AIS patients presenting within 8 hours of symptom onset who were ineligible for IV rt-PA or were IV rt-PA nonresponders were randomized to additional endovascular therapy (mechanical thrombectomy with the Merci retriever or Penumbra System) or no additional acute therapy; patients were stratified based on a favorable penumbra pattern determined prior to treatment by computed tomographic (CT) or magnetic resonance (MR) perfusion imaging. ${ }^{34}$ A favorable penumbral pattern was defined as a predicted infarct core of $\leq 90 \mathrm{cc}$, which also was $<70 \%$ of the tissue at risk. Among 118 eligible patients, the mean time to enrollment was 5.5 hours, and $58 \%$ demonstrated a favorable penumbral pattern. Revascularization was achieved in $67 \%$ of patients in the endovascular arm, with a 90-day mortality of $21 \%$ and an $\mathrm{SICH}$ rate of $4 \%$. Mean scores on the $\mathrm{mRS}$ did not differ between embolectomy and standard care (mean score 3.9 vs. 3.9; $\mathrm{P}=.99$ ). Embolectomy showed no improvement over standard care in those patients with or without a favorable penumbral pattern. ${ }^{34}$

\section{Discussion}

Despite accruing data showing that mechanical devices give higher rates of recanalization than IV rt-PA, there has been difficulty demonstrating a concurrent improvement in patient outcomes. ${ }^{35-38}$ Given the recent failure of several randomized trials to show clinical benefit of endovascular therapy alone or in combination with IV therapy as compared to IV treatment alone, one must ask "Where do we go from here?" The data from IMS III is sound and convincing, making a compelling argument that a combination of IV and IA therapy is not superior to IV therapy alone. However, several main counterpoints must be considered. The trial did not require vascular imaging to document largevessel occlusions or select for IV rt-PA failures, which is often the case with large-vessel occlusions - for which endovascular therapy is currently considered most useful and for which IV therapy is known to have a lower efficacy. ${ }^{5,39}$ Data has further shown decreased efficacy of IV rt-PA for clot burdens $\geq 8 \mathrm{~mm}$ in the middle cerebral artery. ${ }^{40}$ These factors collectively limit the ability of the IMS III trial design to focus evaluation of mechanical devices on the specific subset of AIS patients for whom they are thought to be most useful.

Next, and perhaps more importantly, given the results of the SWIFT and TREVO 2 trials, it must be noted that the majority of IMS III was completed without the use of stent retriever devices. These devices were incorporated into the trial so late that of the 434 patients in the endovascular arm, only 14 patients were treated with stent retrievers. ${ }^{5}$ Given recent data suggesting significant superiority of these devices for vessel recanalization, the data from IMS III must be considered with this potential technical limitation. It is unclear if stent retrievers would have changed the outcome of these recent trials; however, this question must be answered before abandoning mechanical thrombectomy in all but those patients ineligible for IV therapy. This also emphasizes the need for operators to enroll patients in clinical trials whenever possible and to incorporate changes in device technology into the trials as soon as possible to avoid controversial outcomes related to lack of inclusion of current technology. All too often in stroke studies the lag time for trial design and enrollment is being overshadowed by the more quickly evolving technical developments.

In pooled data from endovascular studies including IMS III, it is clear that functional outcome and reduced mortality are associated with decreased times to reperfusion, a factor that mirrors improved outcome seen with earlier administration of IV 
thrombolytics. ${ }^{41-44}$ Future clinical efforts and trials must focus on improving time to patient evaluation and ultimately reperfusion as all treatment strategies hinge on this. We still have an extremely limited understanding of and ability to predict many variables in the setting of AIS, including the amount of reversibly injured and salvageable brain tissue versus core infarction, collateral flow, and clot-specific characteristics that may predict outcomes of intervention. ${ }^{36}$ We do not understand nor can we accurately predict which patients will benefit from reperfusion and which patients will have potentially devastating complications from it. The MR RESCUE trial had hoped to clarify this with perfusion imaging and penumbral characterization but failed, leaving us with even more questions. Hopefully, future investigators will be able to better understand these factors and help.

Conflict of Interest Disclosure: The authors have completed and submitted the Methodist DeBakey Cardiovascular Journal Conflict of Interest Statement and none were reported.

Funding/Support: The authors have no funding disclosures.

Keywords: stroke; thrombolysis; stent retriever

\section{References}

1. Go AS, Mozaffarian D, Roger VL, Benjamin EJ, Berry JD, Borden WB, et al. Heart disease and stroke statistics--2013 update: A report from the American Heart Association. Circulation. 2013 Jan 1;127(1):e6-e245.

2. Heidenreich PA, Trogdon JG, Khavjou OA, Butler J, Dracup K, Ezekowitz MD, et al. Forecasting the future of cardiovascular disease in the United States: a policy statement from the American Heart Association. Circulation. 2011 Mar 1;123(8):933-44.

3. Lloyd-Jones D, Adams RJ, Brown TM, Carnethon M, Dai S, De Simone G, et al. Executive summary: Heart disease and stroke statistics-2010 update: a report from the American Heart Association. Circulation. 2010 Feb 23;121(7):948-54.

4. Rha JH, Saver JL. The impact of recanalization on ischemic stroke outcome: a meta-analysis. Stroke. 2007 Mar;38(3): 967-73.

5. Zaidat OO, Lazzaro MA, Gupta R, Yavagal DR, Rasmussen PA, Hirsch JA, et al. Interventional Management of Stroke III trial: establishing the foundation. J Neurointerv Surg. 2012 Jul;4(4):235-7.

6. Tissue plasminogen activator for acute ischemic stroke. The National Institute of Neurological Disorders and Stroke rt-PA Stroke Study Group. N Engl J Med. 1995 Dec 14;333(24): 1581-7.

7. Cloft HJ, Rabinstein A, Lanzino G, Kallmes DF. Intra-arterial stroke therapy: an assessment of demand and available work force. AJNR Am J Neuroradiol. 2009 Mar;30(3):453-8.

8. Hacke W, Kaste M, Bluhmki E, Brozman M, Davalos A, Guidetti D, et al. Thrombolysis with alteplase 3 to 4.5 hours after acute ischemic stroke. N Engl J Med. 2008 Sept 25;359(13):1317-29.

9. Morgenstern LB, Staub L, Chan W, Wein TH, Bartholomew LK, King M, et al. Improving delivery of acute stroke therapy: The TLL Temple Foundation Stroke Project. Stroke. 2002 Jan;33(1):160-6.

10. Furlan A, Higashida R, Wechsler L, Gent M, Rowley H, Kase C, et al. Intra-arterial prourokinase for acute ischemic stroke. The PROACT II study: a randomized controlled trial. Prolyse in Acute Cerebral Thromboembolism. JAMA. 1999 Dec 1;282(21): 2003-11.
11. Lee M, Hong KS, Saver JL. Efficacy of intra-arterial fibrinolysis for acute ischemic stroke: meta-analysis of randomized controlled trials. Stroke. 2010 May;41(5):932-7.

12. Smith WS, Sung G, Saver J, Budzik R, Duckwiler G, Liebeskind DS, et al. Mechanical thrombectomy for acute ischemic stroke: Final results of the Multi MERCI trial. Stroke. 2008 Apr;39(4):1205-12.

13. Penumbra Pivotal Stroke Trial Investigators. The penumbra pivotal stroke trial: safety and effectiveness of a new generation of mechanical devices for clot removal in intracranial large vessel occlusive disease. Stroke. 2009 Aug;40(8):2761-8.

14. Broussalis E, Trinka E, Hitzl W, Wallner A, Chroust V, KillerOberpfalzer M. Comparison of stent-retriever devices versus the Merci retriever for endovascular treatment of acute stroke. AJNR Am J Neuroradiol. 2013 Feb;34(2):366-72.

15. Dorn F, Stehle S, Lockau H, Zimmer C, Liebig T. Endovascular treatment of acute intracerebral artery occlusions with the solitaire stent: single-centre experience with 108 recanalization procedures. Cerebrovasc Dis. 2012;34(1):70-7.

16. Mordasini P, Brekenfeld C, Byrne JV, Fischer U, Arnold M, Heldner MR, et al. Technical feasibility and application of mechanical thrombectomy with the Solitaire FR Revascularization Device in acute basilar artery occlusion. AJNR Am J Neuroradiol. 2013 Jan;34(1):159-63.

17. Koh JS, Lee SJ, Ryu CW, Kim HS. Safety and efficacy of mechanical thrombectomy with solitaire stent retrieval for acute ischemic stroke: a systematic review. Neurointervention. 2012 Feb;7(1):1-9.

18. Castaño C, Dorado L, Guerrero C, Millán M, Gomis M, Perez de la Ossa N, et al. Mechanical thrombectomy with the Solitaire AB device in large artery occlusions of the anterior circulation: a pilot study. Stroke. 2010 Aug;41(8):1836-40.

19. Mpotsaris A, Bussmeyer M, Loehr C, Oelerich M, Buchner H, Weber W. Mechanical thrombectomy in severe acute stroke: preliminary results of the Solitaire stent. J Neurol Neurosurg Psychiatry. 2012 Jan;83(1):117-8.

20. Stampfl S, Hartmann M, Ringleb PA, Haehnel S, Bendszus M, Rohde S. Stent placement for flow restoration in acute ischemic stroke: a single-center experience with the Solitaire stent system. AJNR Am J Neuroradiol. 2011 Aug;32(7):1245-8.

21. Miteff F, Faulder KC, Goh AC, Steinfort BS, Sue C, Harrington TJ. Mechanical thrombectomy with a self-expanding retrievable intracranial stent (Solitaire AB): experience in 26 patients with acute cerebral artery occlusion. AJNR Am J Neuroradiol. 2011 Jun-Jul;32(6):1078-81.

22. Nguyen T, Maklisch T, Castonguay R, Gupta R, Sun C, Martin C, et al. 0-004 balloon guide catheter improves recanalisation, procedure time, and clinical outcomes with solitaire in acute stroke: Analysis of the nasa registry. J Neurointerv Surg. 2013;5(Suppl 2):A2-A3.

23. Saver J, Jahan R, Levy El, Jovin TG, Baxter B, Nogueira RG, et al. SWIFT Trial Investigators. Solitaire FR with the Intention for Thrombectomy (SWIFT) study. Paper presented at: International Stroke Conference 2012; 2012 Jan 31-Feb 3; New Orleans, LA.

24. Saver JL, Jahan R, Levy El, Jovin TG, Baxter B, Nogueira $R G$, et al. Solitaire flow restoration device versus the Merci Retriever in patients with acute ischaemic stroke (SWIFT): a randomised, parallel-group, non-inferiority trial. Lancet. 2012 Oct 6;380(9849):1241-9. 
25. Nogueira RG, Lutsep HL, Gupta R, Jovin TG, Albers GW, Walker GA, et al. Trevo versus Merci retrievers for thrombectomy revascularisation of large vessel occlusions in acute ischaemic stroke (TREVO 2): a randomised trial. Lancet. 2012 Oct 6;380(9849):1231-40.

26. Turk AS, Spiotta A, Frei D, Mocco J, Baxter B, Fiorella D, et al. Initial clinical experience with the adapt technique: A direct aspiration first pass technique for stroke thrombectomy. J Neurointerv Surg. 2013 Apr 27. [Epub ahead of print]

27. Turk AS 3rd, Campbell JM, Spiotta A, Vargas J, Turner RD, Chaudry Ml, et al. An investigation of the cost and benefit of mechanical thrombectomy for endovascular treatment of acute ischemic stroke. J Neurointerv Surg. 2013 Feb 1. [Epub ahead of print]

28. Tarr R, Hsu D, Kulcsar Z, Bonvin C, Rufenacht D, Alfke K, et al. The post trial: Initial post-market experience of the penumbra system: Revascularization of large vessel occlusion in acute ischemic stroke in the United States and Europe. J Neurointerv Surg. 2010;2(4):341-4.

29. Khatri P, Hill MD, Palesch YY, Spilker J, Jauch EC, Carrozzella JA, et al. Methodology of the interventional management of Stroke III Trial. Int J Stroke. 2008 May;3(2):130-7.

30. Broderick JP, Palesch YY, Demchuk AM, Yeatts SD, Khatri $P$, Hill MD, et al. Endovascular therapy after intravenous t-pa versus t-pa alone for stroke. N Engl J Med. 2013 Mar 7;368(10):893-903.

31. Demchuk A. IMS III: Comparison of outcomes between IV and IV/IA treatment in baseline CTA confirmed ICA, M1, M2, and basilar occlusions. Paper presented at: International Stroke Conference 2013; 2013 Feb 5-8; Honolulu, HI.

32. Grossman AW, Broderick JP. Advances and challenges in treatment and prevention of ischemic stroke. Ann Neurol. 2013 Sep;74(3):363-72.

33. Ciccone A, Valvassori L, Investigators SE. Endovascular treatment for acute ischemic stroke. N Engl J Med. 2013;368:2433-4.
34. Kidwell CS, Jahan R, Gornbein J, Alger JR, Nenov V, Ajani Z, et al. A trial of imaging selection and endovascular treatment for ischemic stroke. N Engl J Med. 2013 Mar 7;368(10):914-23.

35. Tomsick TA, Khatri P, Jovin T, Demaerschalk B, Malisch T, Demchuk A, et al. Equipoise among recanalization strategies. Neurology. 2010 Mar 30;74(13):1069-76.

36. Gorelick PB. Assessment of stent retrievers in acute ischaemic stroke. Lancet. 2012 Oct 6;380(9849):1208-10.

37. Brinjikji W, Rabinstein AA, Kallmes DF, Cloft HJ. Patient outcomes with endovascular embolectomy therapy for acute ischemic stroke: a study of the national inpatient sample: 2006 to 2008. Stroke. 2011 Jun;42(6):1648-52.

38. Baker WL, Colby JA, Tongbram V, Talati R, Silverman IE, White $\mathrm{CM}$, et al. Neurothrombectomy devices for the treatment of acute ischemic stroke: state of the evidence. Ann Intern Med. 2011 Feb 15;154(4):243-52.

39. Saqqur M, Uchino K, Demchuk AM, Molina CA, Garami Z, Calleja S, et al. Site of arterial occlusion identified by transcranial Doppler predicts the response to intravenous thrombolysis for stroke. Stroke. 2007 Mar;38(3):948-54.

40. Riedel $\mathrm{CH}$, Zimmermann P, Jensen-Kondering $U$, Stingele $R$, Deuschl G, Jansen O. The importance of size: successful recanalization by intravenous thrombolysis in acute anterior stroke depends on thrombus length. Stroke. 2011 Jun;42(6):1775-7.

41. Mazighi M, Chaudhry SA, Ribo M, Khatri P, Skoloudik D, Mokin M, et al. Impact of onset-to-reperfusion time on stroke mortality: a collaborative pooled analysis. Circulation. 2013 May 14;127(19):1980-5.

42. Brott T, Reed RL. Intensive care for acute stroke in the community hospital setting. The first 24 hours. Stroke. 1989 May;20(5):694-7.

43. Haley EC Jr, Levy DE, Brott TG, Sheppard GL, Wong MC, Kongable GL, et al. Urgent therapy for stroke. Part II. Pilot study of tissue plasminogen activator administered 91-180 minutes from onset. Stroke. 1992 May;23(5):641-5.

44. Hacke W, Donnan G, Fieschi C, Kaste M, von Kummer R, Broderick JP, et al. Association of outcome with early stroke treatment: pooled analysis of ATLANTIS, ECASS, and NINDS rt-PA stroke trials. Lancet. 2004 Mar 6;363(9411):768-74. 